\title{
Teaching intercultural communication through associative fields of professional vocabulary
}

\author{
Ekaterina Viktorovna Stozhok $^{1^{*}}$, Svetlana Nikolaevna Khalevina $^{2}$, Nina Aleksandrovna \\ Kozlovtseva ${ }^{2}$, and Nadezhda Mamatkulovna Glushkova ${ }^{2}$ \\ ${ }^{1}$ Omsk State Pedagogical University, Department of Foreign Languages, Omsk, Russia \\ ${ }^{2}$ Financial University under the Government of the Russian Federation, Department of Foreign \\ Languages and Intercultural Communication, Moscow, Russia
}

\begin{abstract}
In the era of globalization and social distancing, intercultural dialogue plays a crucial role and requires a thorough reinterpretation. It is impossible without foreign language proficiency. Therefore, teaching foreign languages is a key to professional competency and personal growth. Language reflects the culture and functions as a universal tool of mutual understanding. It makes it possible to embrace the interlocutor's mentality through grasping the peculiarities of the language. The proposed article is devoted to the validity study of the associative field technique. Its application contributes to the successful memorizing of terms and terminological expressions in a foreign language. The research considers the corresponding theoretical background devoted to the issues of intercultural communication, associative fields, and metaphorization of terms and terminological expressions in English. The methods applied in the study include comparative analysis, the method of continuous sampling, and a questionnaire survey. After the survey, the authors identified the terms that evoke associations with the notions "death" and "dead". The article contains a number of interim conclusions with a further perspective on this issue. It is determined that the notion of "death" stands out as a representative of the "naïve" picture of the world and an initially expressive concept. In the case of a formal concept, the notion functions as a successful component of terms, especially metaphorical ones. The results of the study may be implemented in teaching a foreign language and intercultural communication, as well as in comparative linguistics and cultural studies.
\end{abstract}

Keywords: cross-cultural communication, tropes, associative fields, expressiveness, terms and terminological expressions, professional vocabulary

\section{Introduction}

The reality of a globalized world calls for intercultural dialogue. It is necessary to ensure mutual understanding and trust between representatives of different countries and cultures.

*Corresponding author: kategilt@yandex.ru 
The most effective means of setting intercultural communication is the pursuit of foreign language peculiarities and cultures. Any culture is national, which is revealed in the language with the help of a special vision of the world. Each language possesses an internal form, specific to its speakers, and expresses the "national spirit" and its culture, thus, language is an intermediary link between a person and the world around [1]. A number of scientific papers are devoted to the role and peculiarities of mastering intercultural communication while learning a foreign language: Azarova [2], Dervin [3], Fedorova [4], Ganina [5], Ito [6], Klimova [7], Kopus [8], Limar [9], Novikova [10], Sipe [11], Smakhtin [12], Zhang [13], etc. However, the topic of studying intercultural relations is so profound that it requires constant enhancing, including cross-cultural studies.

Trope, as a word or expression used in a figurative sense, is one of the most effective means of intercultural communication. Expressive vocabulary, saturated with vivid images and emotions, helps to improve the communication process, even when it relates to professionally-oriented vocabulary. The reason lies in the fact that many commonly used words have their own affective saturation [14].

is the article aims to show the validity of applying the associative fields method. The use of associations for memorizing terms and terminological expressions in a foreign language may significantly contribute to the process of teaching intercultural communication.

The theoretical basis of the article is represented by prominent publications, especially those devoted to teaching professional vocabulary [1, 15-19, etc.] and other remarkable works $[9,12,20,21]$. The practical value of the research is apparent in the prospects of expanding the professional economic vocabulary while studying foreign languages at specialized universities, as well as in the contribution to memorizing foreign vocabulary with the help of associations.

Associative fields consist of a large number of images, representations, and concepts. Certainly, they differ among representatives of different language communities, especially in the case of specific spheres. The concepts that form the basis of any nationality in any historical period have similar ideas that make up the core of the associative field. In general, the spread of concepts between the core and the periphery of the associative field is not large. The associations that evoke the key concepts of culture have an implicit nature. "Being a product of the intellect, our speech can convey emotion only through implicit associations. The language signs are arbitrary both in their form - the signifier - and in their meaning - the signified, and associations are connected either with the signifier, causing sensory sensations, or with the signified, transforming the concept into an imaginary representation" [14]. The imaginary representations evoked by words denote key concepts of any culture. They are similar among representatives of different linguistic communities, since they possess a formal (and actually national) meaning of the word. "...Formal concepts tend to the sphere of the national language and principally do not tolerate individual deviations. They form the content of words with intersubjective significance. Meaningful concepts, on the contrary, allow for many individual deviations" [22].

\section{$2 \quad$ Methods}

The working hypothesis of the research in the framework of this article is the validity of using associative fields for memorizing emotionally colored words of common speech as terms. In other words, terms and terminological expressions, especially those that include 
lexical units of common speech, contribute to improving communication in a specific professional environment.

In order to confirm or refute this hypothesis, the authors of the article used the following research methods:

1. The continuous sampling method based on terms and terminological expressions from the author's dictionary "English-Russian dictionary of terms conveying the concept of the life path of an object in the economy". Since it is not possible to demonstrate all the examples within the limits of the article, the authors decided to select and analyze the terms containing the word "death". The expression of this noun and its derivatives cause a strong emotional response in recipients.

2. The original questionnaire "Your first associations", designed by the authors of the article;

3. The quantitative and qualitative analysis of the survey results based on the questionnaire;

4. The review of scientific and professional sources and conclusions.

The empirical basis of the research in this article was made up of 1st-2nd-year students of the Omsk Pedagogical University, the Faculty of Philology and Economics. The total number of participants included 63 students aged 18 to 20,12 males and 51 females.

By means of the continuous sampling technique from the author's dictionary "English-Russian dictionary of terms conveying the concept of the life path of an object in the economy", the authors identified 124 terms, 78 of them included the word "death", and 46 terms included the word "dead". At the beginning of the survey, the respondents gathered in one room and got all the necessary instructions. Next, they received the questionnaires "Your first associations" containing a list of stimulus words. After distributing the questionnaires, within 5-10 minutes, the respondents wrote several reaction words, which first came to their mind, next to each stimulus word.

\section{$3 \quad$ Results}

According to the data processing results, the authors singled out 92 words that cause associations to the words "death" or "dead". Then these 92 lexical units were reduced to a number of words with the most frequent associations (from 26 to 5 repetitions). The minimum required is shown in Figure 1. 


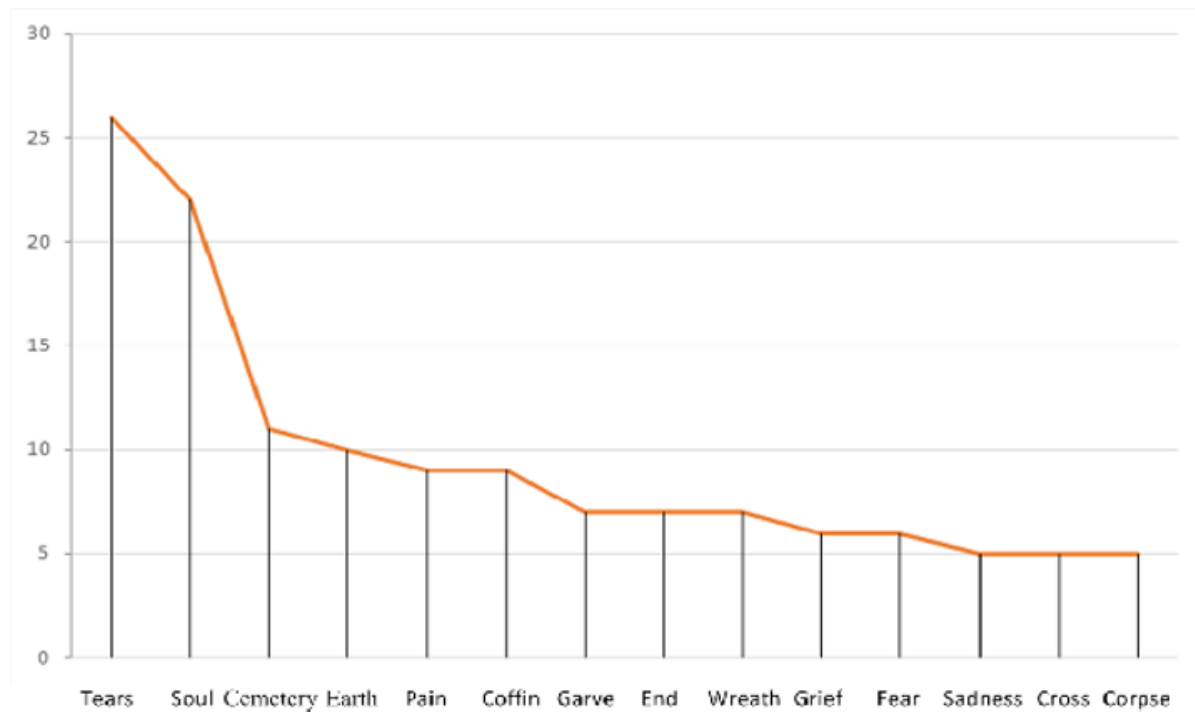

Fig. 1. The frequency of associative repetitions to stimulus words.

Below in Table 1 there is a list of associations to stimulus words in alphabetical order, including the number of respondents who used them.

Table 1. The overall list of associations to stimulus words.

\begin{tabular}{|c|c|c|c|c|c|}
\hline No. & Association & $\begin{array}{c}\text { Frequency } \\
\text { of use }\end{array}$ & No. & Association & $\begin{array}{c}\text { Frequency } \\
\text { of use }\end{array}$ \\
\hline 1. & accident & 1 & 47. & monument & 1 \\
\hline 2. & hell & 2 & 48. & memory & 2 \\
\hline 3. & angel & 1 & 49. & sadness & 3 \\
\hline 4. & pancakes & 1 & 50. & weeping & 3 \\
\hline 5. & illness & 1 & 51. & tranquility & 3 \\
\hline 6. & pain & 9 & 52. & the dead & 1 \\
\hline 7. & hospital & 2 & 53. & wake & 4 \\
\hline 8. & wreath & 7 & 54. & loss & 4 \\
\hline 9. & guilt & 1 & 55. & funeral & 4 \\
\hline 10. & war & 2 & 56. & ghost & 1 \\
\hline 11. & exit & 1 & 57. & past & 1 \\
\hline 12. & woe & 6 & 58. & emptiness & 3 \\
\hline 13. & coffin & 9 & 59. & wasteland & 1 \\
\hline 14. & $\mathrm{sad}$ & 1 & 60. & decomposition & 3 \\
\hline 15. & sadness & 5 & 61. & paradise & 1 \\
\hline 16. & depression & 2 & 62. & investigation & 1 \\
\hline 17. & soul & 22 & 63. & decision & 1 \\
\hline 18. & pity & 2 & 64. & parents & 1 \\
\hline 19. & life & 1 & 65. & freedom & 1 \\
\hline 20. & earth & 10 & 66. & skeleton & 2 \\
\hline 21. & cemetery & 11 & 67. & sorrow & 4 \\
\hline 22. & end & 7 & 68. & tears & 26 \\
\hline 23. & scythe & 2 & 69. & death & 1 \\
\hline 24. & bones & 2 & 70. & regret & 1 \\
\hline 25. & cross & 5 & 71. & condition & 1 \\
\hline 26. & bed & 1 & 72. & old age & 3 \\
\hline
\end{tabular}




\begin{tabular}{|l|c|c|c|c|c|}
\hline 27. & blood & 1 & 73. & suffering & 1 \\
\hline 28. & kutya & 1 & 74. & fear & 6 \\
\hline 29. & forest & 1 & 75. & suicide & 1 \\
\hline 30. & dead man & 1 & 76. & dark & 1 \\
\hline 31. & dead souls & 1 & 77. & darkness & 1 \\
\hline 32. & grave & 8 & 78. & melancholy & 2 \\
\hline 33. & tombstone & 1 & 79. & tragedy & 1 \\
\hline 34. & beginning & 2 & 80. & grieving & 1 \\
\hline 35. & heaven & 1 & 81. & corpse & 5 \\
\hline 36. & inevitability & 2 & 82. & murder & 1 \\
\hline 37. & uncertainty & 1 & 83. & horror & 2 \\
\hline 38. & irreversibility & 1 & 84. & peace & 1 \\
\hline 39. & misunderstanding & 2 & 85. & deprivation & 3 \\
\hline 40. & relief & 1 & 86. & cold & 2 \\
\hline 41. & rite & 1 & 87. & flowers & 4 \\
\hline 42. & fire & 1 & 88. & church & 1 \\
\hline 43. & mourning & 1 & 89. & skull & 1 \\
\hline 44. & rest & 1 & 90. & blackness & 2 \\
\hline 45. & relationships & 1 & 91. & I & 1 \\
\hline 46. & despair & 2 & 92. & pit & 1 \\
\hline & & & & & \\
\hline
\end{tabular}

\section{Discussion}

Among the associations given by the respondents during the experiment, there are not only words with negative connotations but also those related to neutral vocabulary or provocatively pleasant emotions without taking into account the context. The examples can be seen in Table 1 above. Therefore, $83 \%$ of respondents gave words with negative connotations, $17 \%$ indicated neutral or positively colored reaction words. Among the association words, $99 \%$ indicated nouns and only $1 \%$ - adjectives, no other parts of speech were named.

As well as most associations with negative coloring, the recipients indicated almost all terms found using the continuous sampling method with the word "dead" or its derivatives as negative ones. For example: dead account - a blocked account, dead assets - a property that is not profitable, dead bargain - a cheap purchase, dead carriage - (Br.) underutilized cargo capacity or load capacity of the container, dead money - money invested in security with minor hopes of appreciation or earning a return [23].

1. Seven metaphorical expressions stand out from the overall number of studied terms. Their meaning will be difficult to guess, although the notion "dead" implies a negative context: "dead hand" means the control over a property of the trust founder or the testator who died many years ago; "dead in the water" means "to drop hopelessly", "a financial collapse (bankruptcy)" or "to be postponed" [23].

2. Besides, all terms and terminological expressions with the word "death" employ it in its direct meaning, e.g., death annuities - payment of an annual pension in case of the employee's death, tax on transfers by death - the tax on the transfer of property to another owner at the death of the previous one [23].

3. In addition, there is a small number of metaphorical expressions, where "death" acts as a core of a complex expression without direct translation, e.g. death play speculation with company shares, in case of the possible death of the head (e.g., a serious illness) and the subsequent increase in the company value [23]. A Death Valley curve is the stage of risky financing [23]. 
Below one can observe the data from the survey with the question "Do associations help in memorizing terms and terminological expressions, according to your opinion?".

According to the majority of respondents (92\%), this method is effective for memorizing terms, 3\% believe that it is not effective, as associations can interfere with memorizing, and $5 \%$ of respondents are not sure about the answer. The results are shown in Figure 2.

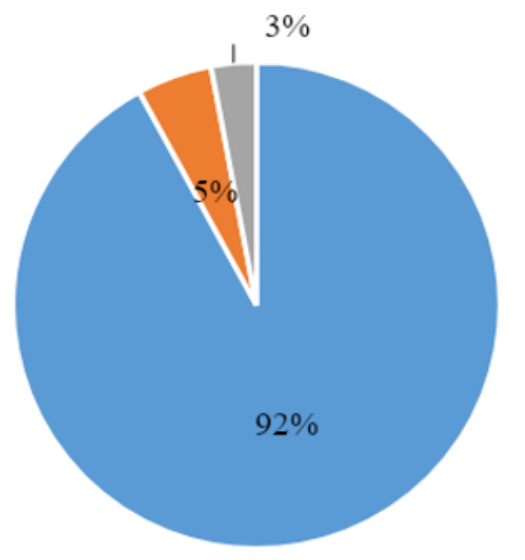

Effective for

memorizing

Not effective for

memorizing

Not sure

Fig 2. Do associations help in memorizing terms and terminological expressions, according to your opinion?

Based on the diagram, it is possible to conclude that the purpose of this study has been achieved. The survey proved the validity of the associative fields method used for memorizing terms and terminological expressions in a foreign language.

\section{$5 \quad$ Conclusions}

In view of the above, it is possible to make preliminary conclusions:

1. The associative series of the research are mostly negative, as well as the terms and terminological expressions selected for the experiment. This fact proves the working hypothesis about the validity of using associative series for memorizing emotionally colored words of common speech as terms.

2. According to the majority of respondents, associations contribute to students' better visualization of a term or terminological expression and improves the memorizing process through a vivid image of a notion.

3. Terms and terminological expressions, especially those including lexical units of common speech, foster communication in a specific professional environment.

4. The notion of "death" represents the "naïve" picture of the world, being an initially expressive concept. Besides, it functions as a formal concept, whose associative field does not have a profound gap between less frequent and more frequent associations that might cause an interpretation disbalance. This notion is a successful component of terminological expressions, especially metaphorical ones.

5. In general, any "language transformations are significantly based on re-nomination, emotional and pragmatic factors" [24]. 


\section{References}

1. Humboldt, V. Yazyk i filosofiya kul'tury [Language and philosophy of culture] (Progress, Moscow, 1985)

2. O.A. Azarova, et al., J Environ Manag Tourism, 10(6(38)), 1376-1381 (2019). https://doi/10.14505/jemt.v10.6(38).20

3. F. Dervin, A. Jacobsson, Teacher Edu Crit Reflex Intercult, 67-73 (2021). https://doi/10.1007/978-3-030-66337-7_8

4. E.A. Fedorova, et al., IJEAT-BEIESP, 9(1), 4532-4535 (2019). https://doi/10.35940/ijeat.A1785.109119

5. E.V. Ganina, et al., Int J Eng Adv Tech, 9(1), 5565-5569 (2019). https://doi/10.35940/ijeat.A2128.109119

6. Y. Ito, The study of idioms and its application to ESL and intercultural communication. Master's Theses, 632 (San Jose State University, 1993). https://doi.org/10.31979/etd.jnxy-8edr

7. I.I. Klimova, G.V. Klimova, S.A. Dubinka, XLinguae, 12(1), 207-218 (2019). https://doi/10.18355/XL.2019.12.01.16

8. I.I. Klimova, T.L. Kopus, Designing Online Course for Curriculum Internationalizing: Blended Learning Format, in Proc. 13th International Technology, Education and Development Conference (Inted2019). Valencia, Spain, 3080-3085 (2019). https://doi/10.21125/inted.2019.0814

9. M.P. Limar, Vostok. Afro-Asian Soc: Hist Modern, (3), 67-78 (2019). https://doi/10.31857/S086919080005239-9

10. Y.B. Novikova, et al., XLinguae, 10(4), 369-380 (2017). https://doi/10.18355/XL.2017.10.04.30

11. M. Sipe, J. Saludadez, J Intercult Comm Res, 1-16 (2021). https://doi/10.1080/17475759.2021.1932559

12. E.S. Smakhtin, et al., XLinguae, 11(3), 103-113 (2018). https://doi/10.18355/XL.2018.11.03.10

13. Y. Zhang, English Lang Teach, 10(11), 229 (2017). https://doi/10.5539/elt.v10n11p229

14. Ch. Bally, Yazyk i zhizn' [Language and life] (Editorial URSS, Moscow, 2018)

15. I.V. Arnold, Osnovy nauchnykh issledovanii v oblasti lingvistiki [Fundamentals of scientific research in linguistics] (Higher School, Moscow, 1991)

16. N.Yu. Borodulina, Metaforicheskoe predstavlenie ekonomicheskikh ponyatii kak obyekt semioticheskogo analiza [Metaphorical representation of economic concepts as an object of semiotic analysis] (Gramota, Moscow, 2007)

17. H. Hsu, JALT CALL, 14, 119-142 (2018). https://doi/10.29140/jaltcall.v14n2.227

18. M. Łukasik, Poliog Stud Neofil, 7, 301-314 (2017)

19. A. Vezhbitskaya, Semanticheskie universalii i opisanie yazykov [Semantic universals and the description of languages] (Languages of Russian culture, Moscow, 1999)

20. L.A. Gavrilov, R.I. Zaripov, A.S. Romanov, Polit Linguist, 4, 91-95 (2017)

21. N. Sarifa, Int J Linguist Literat Transl, 1(4), 44-47 (2018) 
22. A.V. Superanskaya, N.V. Podolskaya, N.V. Vasilyeva, Obshchaya terminologiya: Voprosy teorii [General terminology: Questions of theory] (Librocom, Moscow, 2012)

23. E.V. Stozhock, Anglo-russkii slovar' terminov, peredayushchii ponyatie zhiznennogo puti obyekta $\mathrm{v}$ ekonomike [English-Russian dictionary of terms conveying the concept of the life path of an object in the economy] (Publishing house "Center of printing Pulsar-98", Omsk, 2011)

24. N.D. Arutyunova, Yazyk i chelovecheskii mir. Yazyki russkoi kul'tury [Language and the human world. Languages of Russian culture] (Languages of Russian culture, Moscow, 1999) 